\title{
A Low-Profile Antenna Based on Single-Layer Metasurface for Ku-Band Applications
}

\author{
Yadgar I. Abdulkarim $\mathbb{i}^{1,2}$ Halgurd N. Awl, ${ }^{3}$ Fahmi F. Muhammadsharif ${ }^{1}{ }^{4}$ \\ Muharrem Karaaslan, ${ }^{5}$ Rashad H. Mahmud, ${ }^{6}$ Sattar O. Hasan, ${ }^{6}$ Ömer Işık $\mathbb{D}^{\mathbb{7}}{ }^{7}$ Heng Luo, ${ }^{1}$ \\ and Shengxiang Huang ${ }^{1}$
}

\author{
${ }^{1}$ School of Physics and Electronics, Central South University, Changsha, Hunan 410083, China \\ ${ }^{2}$ Physics Department, College of Science, University of Sulaimani, Sulaimani 46001, Iraq \\ ${ }^{3}$ Department of Communication, Engineering College, Sulaimani Polytechnic University, Sulaimani 46001, Iraq \\ ${ }^{4}$ Department of Physics, Faculty of Science and Health, Koya University, Koya 44023, Iraq \\ ${ }^{5}$ Department of Electrical and Electronics, Iskenderun Technical University, Hatay 31100, Turkey \\ ${ }^{6}$ Department of Physics, Salahaddin University, Erbil 44001, Iraq \\ ${ }^{7}$ Department of Electrical and Electronics, Beykent University, Istanbul 34100, Turkey
}

Correspondence should be addressed to Shengxiang Huang; hsx351@csu.edu.cn

Received 14 September 2020; Revised 12 November 2020; Accepted 30 November 2020; Published 16 December 2020

Academic Editor: María Elena de Cos Gómez

Copyright (C) 2020 Yadgar I. Abdulkarim et al. This is an open access article distributed under the Creative Commons Attribution License, which permits unrestricted use, distribution, and reproduction in any medium, provided the original work is properly cited.

\begin{abstract}
Improvement in the antenna gain is usually achieved at the expense of bandwidth and vice versa. This is where the realization of this enhancement can be made through compromising the antenna profile. In this work, we propose a new design of incorporating periodic metasurface array to enhance the bandwidth and gain while keeping the antenna to a low-profile scheme. The proposed antenna was simulated and fabricated in order to validate the results in the operating frequency range from $10 \mathrm{MHz}$ to $43.5 \mathrm{GHz}$. Computer simulation technology (CST) microwave studio software was used to design and simulate the proposed antenna, while LPKF prototyping PCB machine was utilized to fabricate the antenna. Results showed that the antenna generated a gain and bandwidth of $14.2 \mathrm{~dB}$ and $2.13 \mathrm{GHz}$, respectively. Following the good agreement between the numerical and measurement results, it is believed that the proposed antenna can be potentially attractive for the application of satellite communications in Ku-band electromagnetic wave.
\end{abstract}

\section{Introduction}

The contribution of patch antennas in different applications has been well acknowledged, thanks to their low cost, low profile, and simple fabrication process despite their relatively narrow bandwidth and low gain [1]. For instance, AlSabbagh et al. reported a compact triple-band metamaterial-inspired antenna for wearable applications [2], Coburn and McCormick developed an ultra-wideband antenna for radar applications [3], Al-Janabi and Kayhan proposed a flexible Vivaldi antenna based on fractal design for harvesting the radio frequency (RF) energy in low-powered portable devices [4], and Naiemy et al. designed, fabricated, and tested a monopole antenna based on electromagnetic band gap structure for GSM and WiMAX applications [5].

Motivated by the bandwidth and gain limitation of patch antennas, different approaches were reported by researchers with the aim of tackling this issue [6-9]. In this way, metasurface-based microstrip antennas were introduced as an alternative approach to improve the conventional microstrip antennas. The role of metasurface structures in the design aspects of microstrip antennas has been intensively studied [10-14]. For instance, a periodic metasurface structure was integrated into the microstrip antenna, thereby converting the linear polarization to circular polarization without modifying the antenna feeding line 
$[15,16]$. To achieve a wide bandwidth antenna, an array of corner-truncated metasurface cell was incorporated into a microstrip feeding structure [17]. Moreover, a metamaterial was placed around a periodic cell array of printed patch antenna aiming at enhancing the power gain [18]. Notably, there are different metamaterial structures, known as resonators, that are utilized to control the antenna resonant frequencies and bandwidth. Examples of these structures are spiral resonator [19] and modified rectangular resonator. They are usually placed on metamaterial frames in order to realize negative refraction index at desired operating frequencies [20]. This can be an effective approach whenever designing a multiband antenna is targeted. A low-profile dual-band antenna was proposed, which is based on embedding the main antenna structure between two layers of metasurface [21]. The antenna yielded two gain peaks at $7.6 \mathrm{~dB}$ and $6.8 \mathrm{~dB}$ due to bidirectional radiation from both sides. Also, a coplanar waveguide (CPW) was coupled to a broadband metasurface array in order to feed all the inphase cells [22]. This approach has made the antenna array to get a significant impedance bandwidth of $67.31 \%$ with a low profile and $9.18 \mathrm{~dB}$ gain. Another wide bandwidth metasurface antenna was proposed, which is based on stepped impedance resonator (SIR) [23]. As a result of SIR inclusion, the antenna produced $31 \%$ impedance bandwidth and $7.9 \mathrm{~dB}$ gain with a miniaturized size. Furthermore, researchers attended to enhance the performance of a square microstrip patch antenna by placing a $4 \times 4$ metasurface layer above the patch [24]. A metasurface superstrate was also used to design a circularly polarized antenna for satellite applications [25].

The intensive and extensive review of literature revealed that most of the attempts to improve the antenna gain have been made at the expense of bandwidth and vice versa. Therefore, it is crucial to maximize both high gain and bandwidth of the antennas when an improvement approach is considered. Along this line, using multilayer substrates to include a metasurface layer can be one of the possible techniques to improve the gain without compromising the bandwidth performance. For example, a multilayer metasurface antenna was reported to provide a wide bandwidth at the gain of $24.2 \mathrm{~dB}$ [26]. Furthermore, a significant improvement in the antenna gain and bandwidth was achieved by placing the metasurface layer below the antenna array [27]. Complex feeding networks and cavity period-based metasurface were also used to enhance the gain and bandwidth of antennas [28-30]. However, it is evidenced from the results of literature that antennas' profile (size) is usually sacrificed when extra layers or complex feeding networks are utilized to improve the gain and bandwidth [31]. Therefore, in the current work, we propose a new design of incorporating periodic metasurface array to enhance the bandwidth and gain while keeping the antenna to a low-profile scheme. The proposed antenna was simulated and fabricated in order to validate the results in the operating frequency range from $10 \mathrm{MHz}$ to $43.5 \mathrm{GHz}$. Following the excellent agreement between the numerical and measurement results, it is believed that the proposed antenna can be potentially attractive for the application of satellite communications.

\section{Materials and Methods}

The proposed antenna is made of two flame-retardant (FR4) substrates, on which the feeding and metasurface layers are deposited. The substrates are separated by an air gap of $11.3 \mathrm{~mm}$, as shown in Figure 1(a). The selection of FR4-type substrate is because of its low dielectric loss, high mechanical strength, and low cost. The FR4 thickness is $1.6 \mathrm{~mm}$ having a dielectric constant of 4.3 and loss tangent of 0.025 . The single-layer metasurface (Figure 1(c)) was deposited on the upper FR4. The ground plane is copper film with a thickness of $0.035 \mathrm{~mm}$ and conductivity of $5.96 \times 10^{7} \mathrm{~S} / \mathrm{m}$. Two unequal slots, namely, $S_{1}$ and $S_{2}$, were generated within the ground plane of the lower FR4 substrate with dimensions of $9.4 \times 1.5 \mathrm{~mm}^{2}$ and $17.5 \times 1 \mathrm{~mm}^{2}$, respectively. They were coupled to the feeding port (microstrip line) via a point from the antenna centre, known as step load, by means of a $50 \Omega$ SMA connector, as shown in Figure 2(c). The outer part of the SMA was connected to the ground plane, and the inner part was extended through the substrate to be connected with the microstrip strip. For the designed structure and simulation analysis, finite integration technique (FIT) and CST microwave studio were used. The required dimensions of the proposed structure were determined by using parametric studies and genetic algorithm approach in order to operate the antenna in the Ku-band, making it useful for the application of satellite communication. The dimension of the metasurface was considered to be $80 \times 80 \mathrm{~mm}^{2}$. The other physical dimensions of the designed antenna are given in Table 1.

The proposed antenna was fabricated using the E33 model of LPKF prototyping PCB machine. After the fabrication of each layer, a $50 \Omega$ SMA connector was soldered to the feeding/microstrip line and ground plane of the structure, as shown in Figure 2. The measurement was carried out by using PNA-L Agilent vector network analyzer (VNA) in the frequency range from $10 \mathrm{MHz}$ to $43.5 \mathrm{GHz}$. Initially, the VNA was calibrated using a proper calibration kit, utilizing the short circuit, open circuit, and load apparatus. The calibration of VNA was realized in the frequency range of the antenna operation from 5 to $18 \mathrm{GHz}$. Finally, the antenna was connected to the VNA, and the return loss parameter was measured.

\section{Results and Discussion}

The simulation results of the proposed antenna were first validated using the tools of CST microwave studio and highfrequency simulator structure (HFSS). Figure 3 shows the return loss spectra that were recorded by the tools, implying a good agreement and validation of the proposed design. One can notice the presence of three main resonant frequencies of the antenna at $12.5 \mathrm{GHz}, 14.2 \mathrm{GHz}$, and $16 \mathrm{GHz}$.

Figure 4 shows the simulation result of the gain spectrum for the metasurface-based antenna in the frequency range 


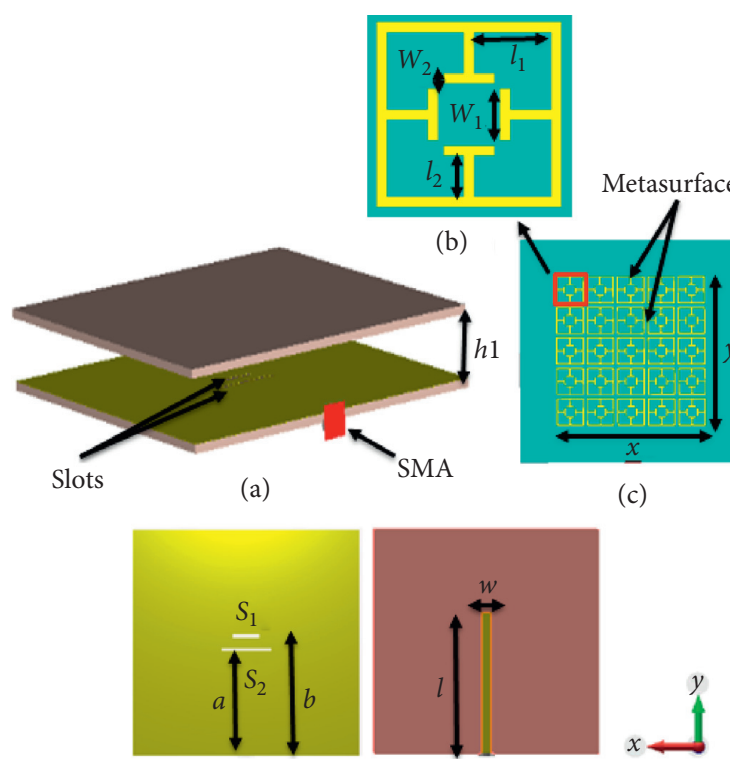

(d)

(e)

Figure 1: Schematic diagram of the proposed antenna (a), front view of a unit cell of the metasurface (b), metasurface layer (c), back view of the ground plane with slots (d), and front view with the microstrip line (e).

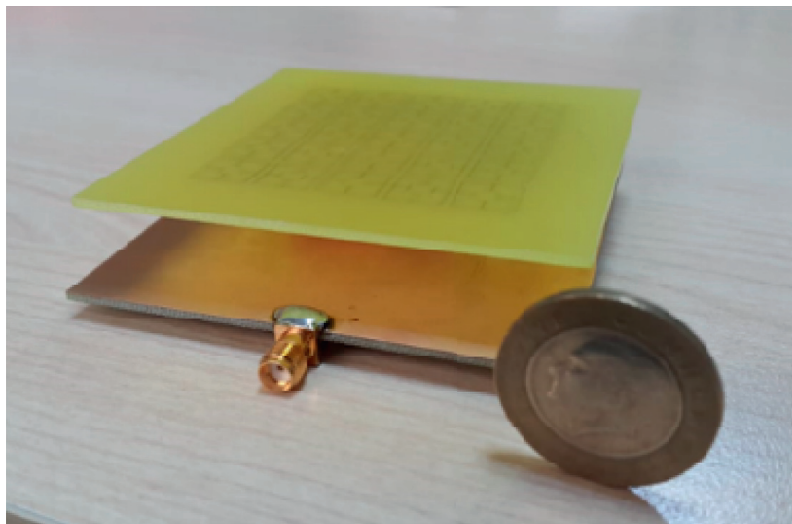

(a)
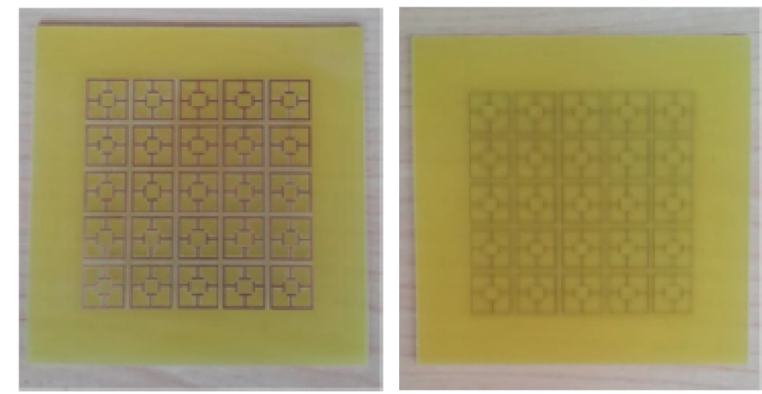

(b)
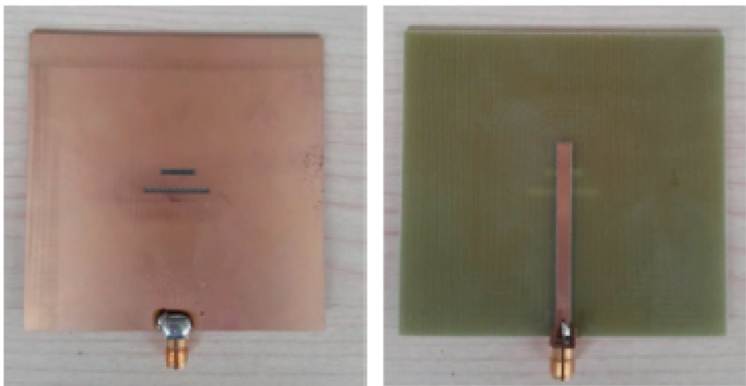

(c)

Figure 2: Photograph of the fabricated antenna with single-metasurface layer (a), both sides of the metasurface (b), and the front and back sides of the feeding structure (c).

from 12 to $18 \mathrm{GHz}$. The bandwidth and gain of the antenna were found to be $1.65 \mathrm{GHz}$ and $14.2 \mathrm{GHz}$, respectively. Results showed that the bandwidth and gain of the proposed antenna outperformed those reported in literature for the other antennas, as shown in Table 2.
The directivity of the proposed antenna was calculated to be $17.3 \mathrm{~dB}$ at the frequency of $14.2 \mathrm{GHz}$, as shown in Figure 5 . The gain response is usually correlated with the response of antenna reflection coefficient $\left(S_{11}\right)$. This means that if the antenna resonates at a certain operating frequency 
TABLE 1: Dimensions of the proposed antenna used in the simulation design.

\begin{tabular}{lc}
\hline Parameters & Value $(\mathrm{mm})$ \\
\hline$l_{1}$ & 4.175 \\
$l_{2}$ & 6.66 \\
$w_{1}$ & 0.55 \\
$w_{2}$ & 3.88 \\
$L$ & 50.5 \\
$W$ & 3.6 \\
$a$ & 36.6 \\
$b$ & 41.25 \\
$x$ & 54 \\
$y$ & 54 \\
$h$ & 11.3 \\
\hline
\end{tabular}

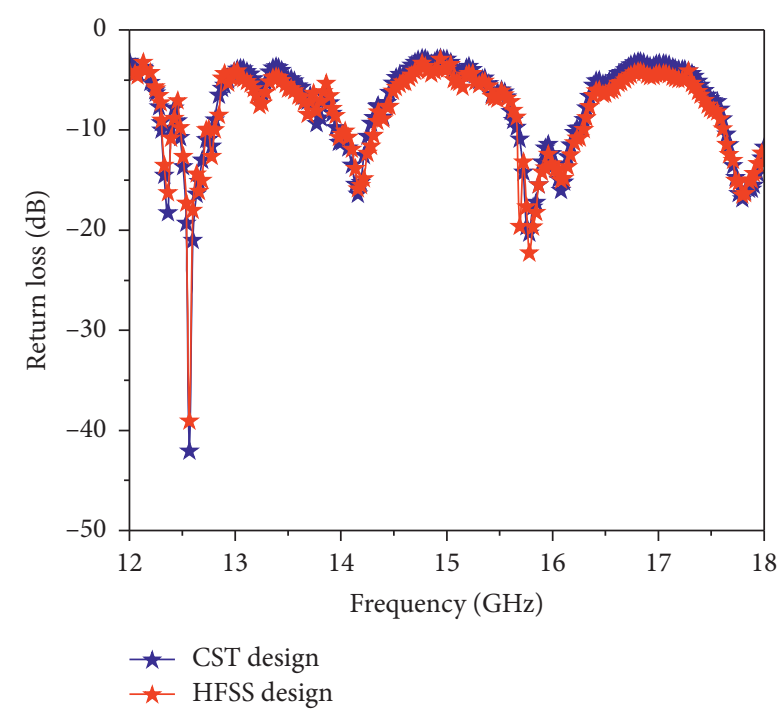

FIGURE 3: Return loss of the proposed antenna recorded from two different tools.

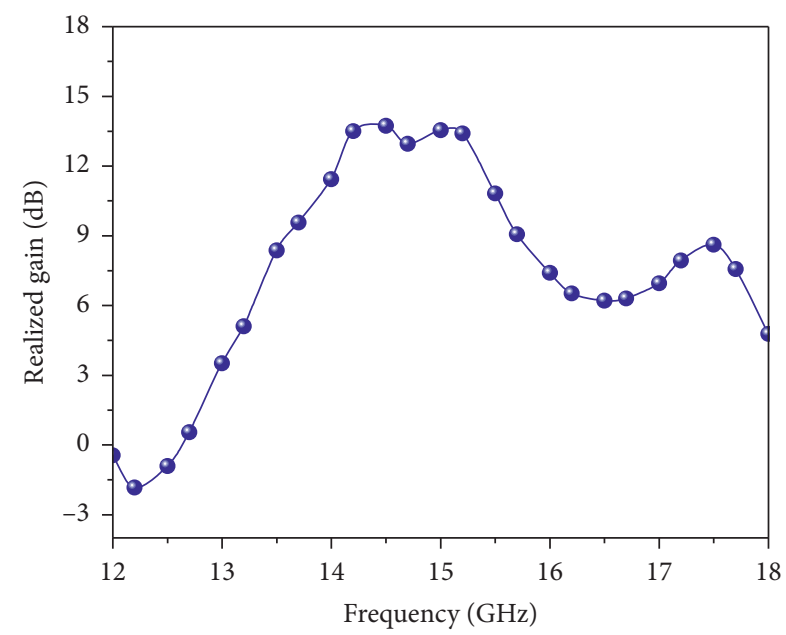

FIGURE 4: Realized gain spectrum for the single-layer metasurfacebased antenna.

point, a good gain response is expected at that point. However, this is true only if the radiating dimensions (areas) of the antenna support the electromagnetics to launch to free space (supporting EM modes to propagate).

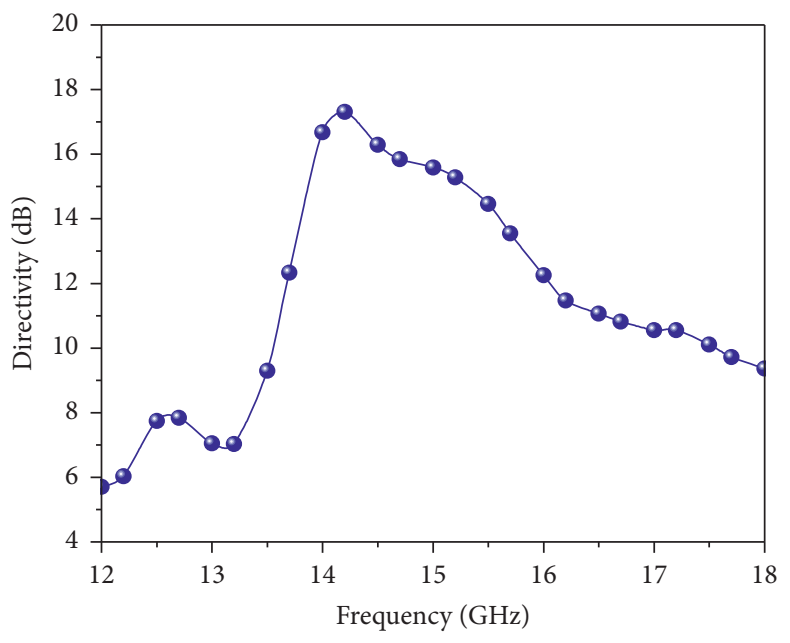

FIGURE 5: Simulated result of directivity for the proposed antenna based on single-layer metasurface.

TABLE 2: Comparison of the proposed antenna with those reported in literature.

\begin{tabular}{|c|c|c|c|c|}
\hline Ref. & Size $(\mathrm{mm})$ & $\begin{array}{l}\text { Frequency } \\
\quad(\mathrm{GHz})\end{array}$ & $\begin{array}{c}\text { Bandwidth } \\
(\mathrm{GHz})\end{array}$ & $\begin{array}{l}\text { Peak } \\
\text { gain } \\
\text { (dB) }\end{array}$ \\
\hline [13] & $42 \times 42 \times 10$ & $4.42-6.22$ & 1.8 & 11 \\
\hline [19] & $63 \times 108 \times 1$ & $1.85-5.65$ & 3.8 & 7.32 \\
\hline [20] & $\begin{array}{c}60 \times 0.787 \\
\text { Circular }\end{array}$ & $5.89-6.6$ & 0.71 & 9.8 \\
\hline [32] & $59 \times 59 \times 3.25$ & $4.77-6.52$ & 1.75 & 9 \\
\hline [33] & $69 \times 69 \times 67$ & 5.1-6 & 0.9 & 9.85 \\
\hline [34] & $69 \times 69 \times 68$ & $4-6.5$ & 2.5 & 11.6 \\
\hline $\begin{array}{l}\text { This } \\
\text { work }\end{array}$ & $80 \times 80 \times 14.5$ & $12-14.13$ & 2.13 & 14.2 \\
\hline
\end{tabular}

The variation in directivity, gain, and total efficiency versus operating frequency of the proposed antenna with single-layer metasurface is shown in Figure 6. One can observe that the antenna has yielded a peak gain of $14.2 \mathrm{~dB}$ at 14.2 GHz. The average of total efficiency was found to be more than $55 \%$ over the operating frequency of interest. It is worth to mention that further investigations on the enhancement of the antenna bandwidth can be considered through the inclusion of various architectural designs of the metasurface layer. 


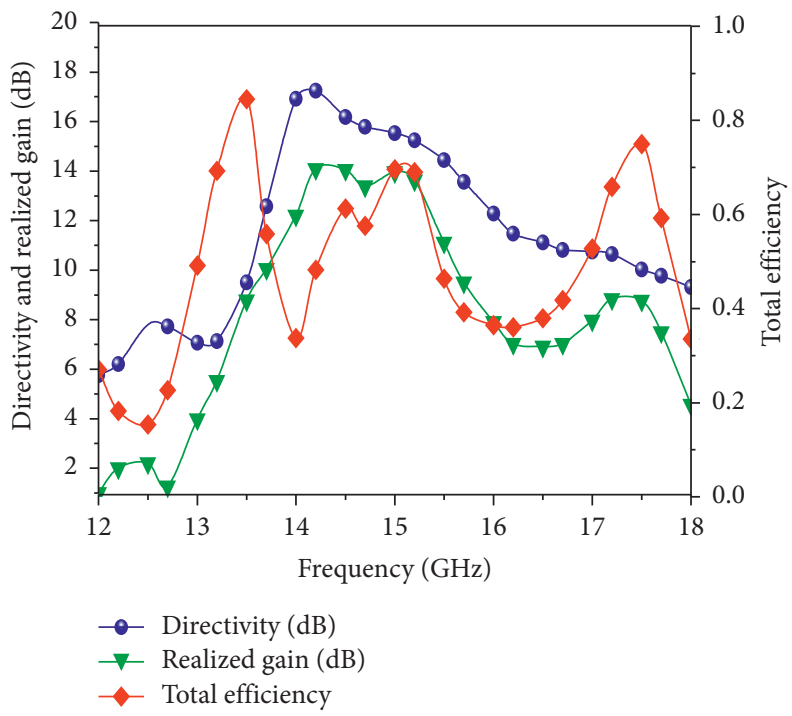

FIGURE 6: Variation in directivity, gain, and efficiency of the proposed antenna versus frequency.

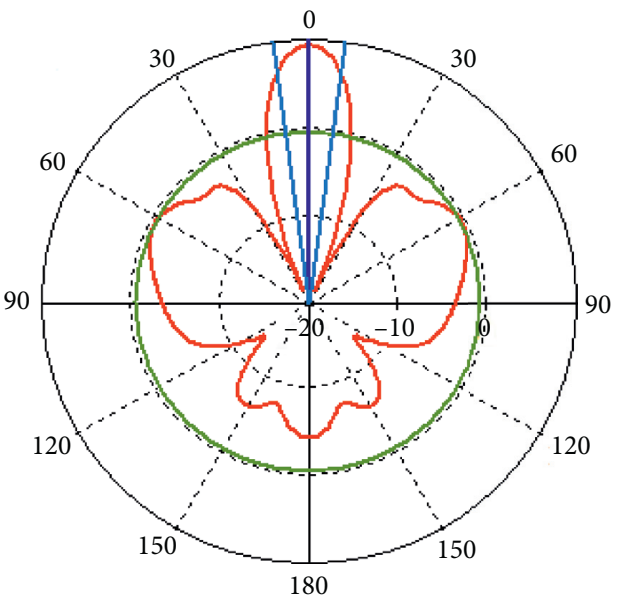

(a)

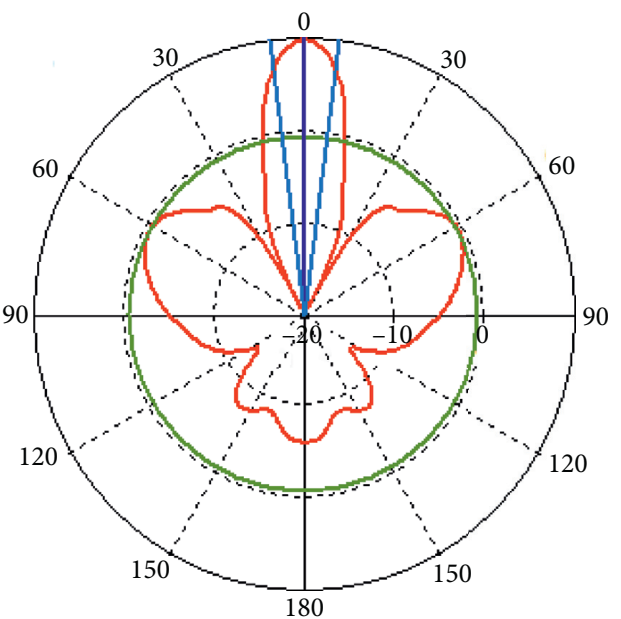

(c)

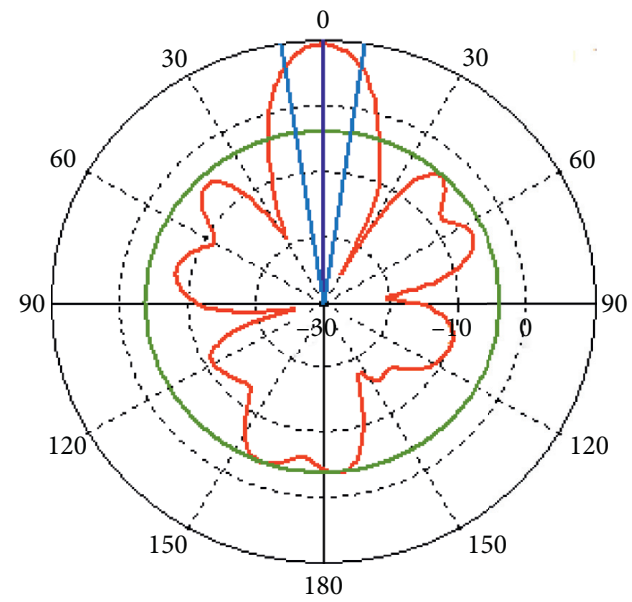

(b)

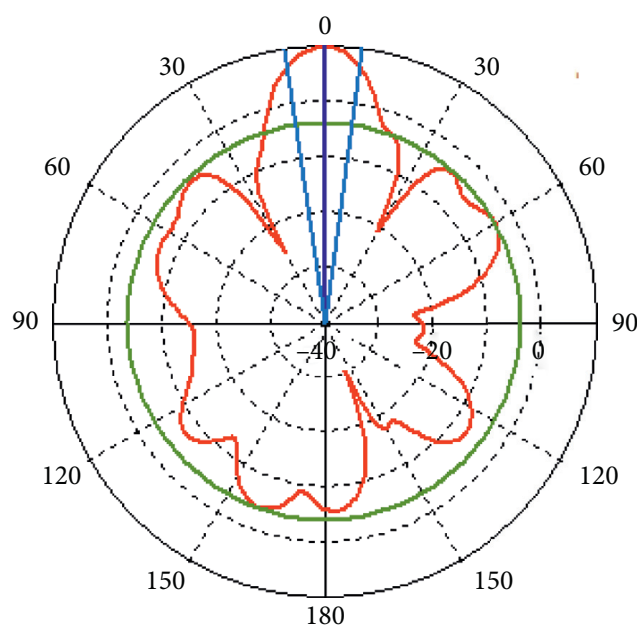

(d)

Figure 7: Simulated radiation patterns at the frequency of $14 \mathrm{GHz}$ for (a) E-plane and (b) H-plane and at $14.2 \mathrm{GHz}$ for (c) E-plane and (d) H-plane. 


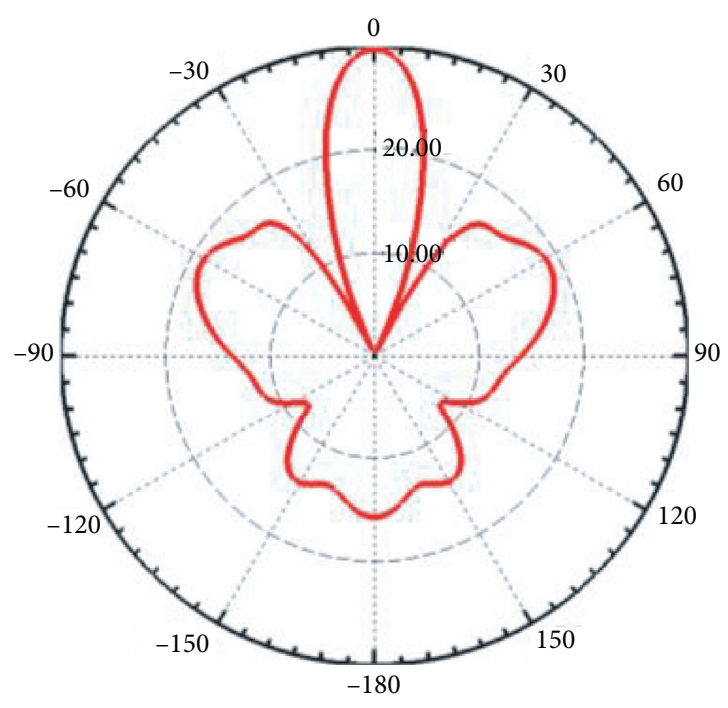

(a)

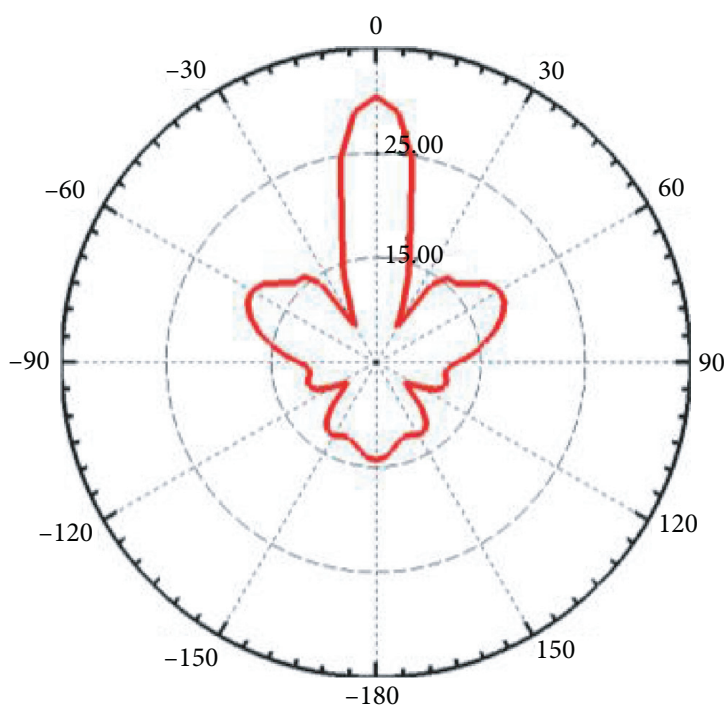

(c)

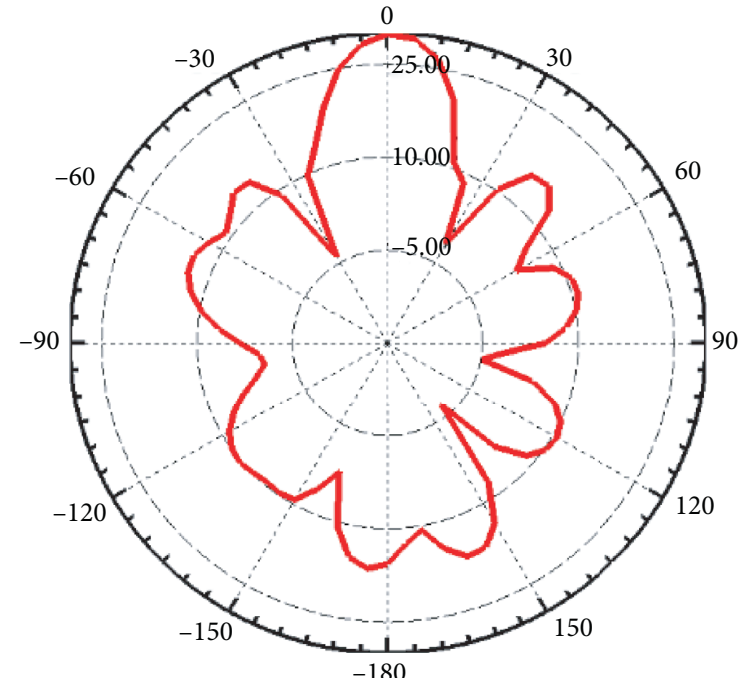

(b)

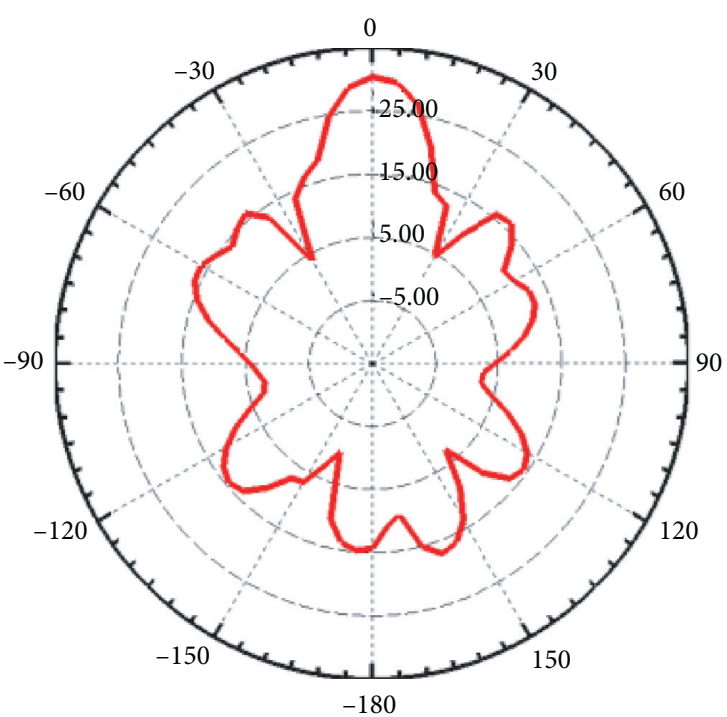

(d)

Figure 8: Simulated radiation patterns in HFSS software at $14 \mathrm{GHz}$ for (a) E-plane and (b) H-plane and at $14.2 \mathrm{GHz}$ for (c) E-plane and (d) H-plane.

A comparison of the proposed antenna with those reported in literature was performed in terms of profile (overall size), bandwidth, and gain, as shown in Table 2 . Notably, the proposed antenna has provided a relatively better gain and bandwidth compared to those reported in literature, while the profile of the proposed antenna is reasonably comparable to those of the reported antennas. It is concluded that the proposed single-layer metasurface can be a potential candidate for the application of satellite communications in $\mathrm{Ku}$-band electromagnetic spectrum.

The radiation patterns in the $\mathrm{E}$ - and $\mathrm{H}$-planes were simulated at the characteristic frequencies of $14 \mathrm{GHz}$ and 14.2 GHz, as shown in Figure 7. It can be seen that the patterns attained low side lobe levels, especially in the $\mathrm{H}$-plane, which is below $-15 \mathrm{~dB}$ at $14 \mathrm{GHz}$. Notably, the side lobe levels were found to increase with the increase in the operating frequency.
The antenna was also simulated in the high-frequency structure simulator (HFSS) in order to validate the radiation patterns. Notably, a good agreement between the two simulation results was obtained, as shown in Figure 7. The antenna provided a single main lobe with a small beam width towards 0 degrees at both frequencies. However, lower side lobes can be seen at the H-plane, while the back-lobe level was increased compared to that of the E-plane (Figure 8).

Figure 9 shows the measured and simulated return loss of the proposed antenna. A small deviation of the measured return loss from that of the simulated one was observed at high frequencies. This can be due to the following reasons: first, it is not guaranteed that soldering the SMA connector with the feeding line provides the same theoretical value of $50 \Omega$, so some losses and unexpected reflection may occur due to this mismatching. Second, the fabrication technology 


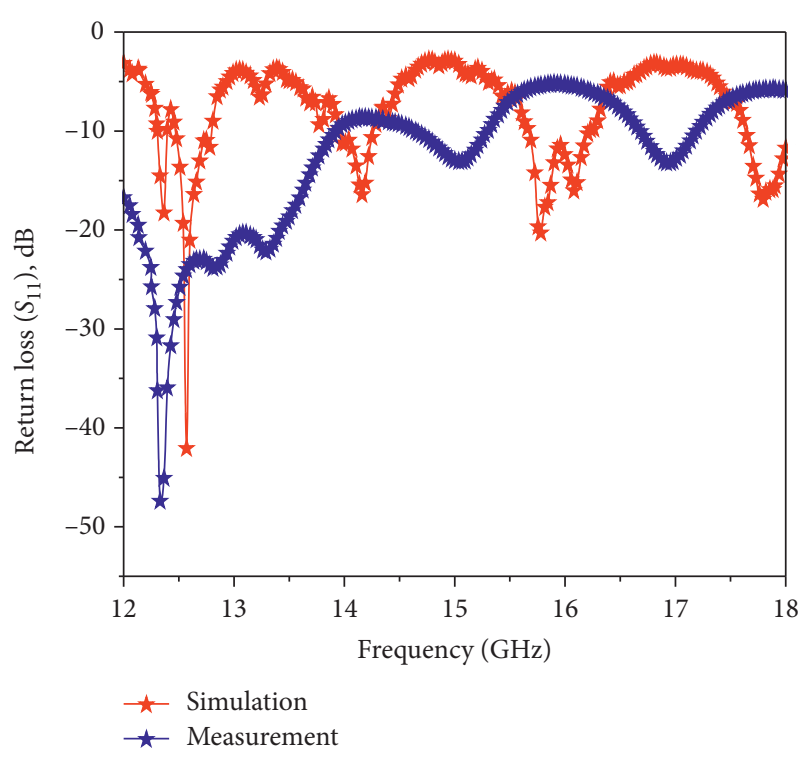

FIgURE 9: Measured and simulated return loss of the antenna.

is limited by some tolerances. The technology used to fabricate the antenna here has a tolerance of around $\mp 1 \mathrm{~mm}$. Further improvements can be obtained by considering an enhanced fabrication tolerance to below $\mp 0.4 \mathrm{~mm}$. It was seen that the measured $-10 \mathrm{~dB}$ impedance bandwidth is $2.13 \mathrm{GHz}$ from 12 to $14.13 \mathrm{GHz}$.

\section{Conclusion}

The utilization of a single-layer metasurface was successfully proposed to simulate and fabricate a high gain and bandwidth antenna of a reasonably low-profile scheme. The simulation results from CST microwave studio and HFSS tools were found to be in good agreement with the experimental one. Results showed the presence of three characteristic resonant frequencies of the antenna. Consequently, the bandwidth and gain of the proposed antenna outperformed those reported in literature for the other antennas. It is concluded that the proposed single-layer metasurface can be a potential candidate for the application of satellite communications in the $\mathrm{Ku}$-band electromagnetic spectrum.

\section{Data Availability}

No data were used to support this study.

\section{Conflicts of Interest}

The authors declare that there are no conflicts of interest.

\section{Authors' Contributions}

H.N.A. and Y.I.A. conceptualized the study. H.N.A., Y.I.A., and R.H.M. prepared methodology. H.N.A. analyzed using software. M.K., L.D., and Y.I.A. validated the study. H.N.A., R.H.M., and F.F.M. performed formal analysis. H.N.A. investigated the study. F.F.M. was responsible for managing resources. H.N.A. curated the data. H.N.A. and Y.I.A. wrote the original data. R.H.M., F.F.M., S.O.H., O. I., SH.H., and H.L. reviewed and edited the study. H.N.A. visualized the study. M.K. and L.D. supervised the study. M.K. administrated the project.

\section{Acknowledgments}

This work was supported by the National Key Research and Development Program of China (Grant no. 2017YFA0204600), National Natural Science Foundation of China (Grant no. 51802352), and Fundamental Research Funds for the Central Universities of Central South University (Grant no. 2018zzts355).

\section{References}

[1] C. A. Balanis, Antenna Theory: Analysis and Design, John Wiley \& Sons, Hoboken, NJ, USA, 2016.

[2] H. M. AlSabbagh, T. A. Elwi, Y. Al-Naiemy, and H. M. AlRizzo, "A compact triple-band metamaterial-inspired antenna for wearable applications," Microwave and Optical Technology Letters, vol. 11, pp. 1-15, 2019.

[3] W. Coburn and S. McCormick, "Ultra-wideband antenna performance comparison," in Proceedings of the International Applied Computational Electromagnetics Society Symposium (ACES), pp. 1-2, Denver, CO, USA, March 2018.

[4] M. A. Al-Janabi and S. K. Kayhan, "Flexible vivaldi antenna based on a fractal design for RF-energy harvesting," Progress in Electromagnetics Research M, vol. 97, pp. 77-188, 2020.

[5] Y. A. Naiemy, T. A. Elwi, and L. Nagy, "An end fire printed monopole antenna based on electromagnetic band gap structure," Automatika, vol. 61, pp. 482-495, 2020.

[6] H. N. Awl, Y. I. Abdulkarim, L. Deng et al., "Bandwidth improvement in bow-tie microstrip antennas: the effect of substrate type and design dimensions," Applied Sciences, vol. 10, no. 2, p. 504, 2020.

[7] O. Losito, V. Portosi, G. Venanzoni et al., "Feasibility investigation of SIW cavity-backed patch antenna array for $\mathrm{Ku}$ band applications," Applied Science, vol. 9, 2019.

[8] N. Kushwaha and R. Kumar, "Design of slotted ground hexagonal microstrip patch antenna and gain improvement with FSS screen," Progress In Electromagnetics Research B, vol. 51, pp. 177-199, 2013.

[9] A. Birwal, S. Singh, B. K. Kanaujia, and S. Kumar, "Broadband CPW-fed circularly polarized antenna for IoT-based navigation system," International Journal of Microwave and Wireless Technologies, vol. 11, no. 8, pp. 835-843, 2019.

[10] M. Z. Mahmud, M. T. Islam, N. Misran, M. J. Singh, and K. A. Mat, "Negative index metamaterial to enhance the performance of miniaturized UWB antenna for microwave imaging applications," Applied Science, vol. 7, 2017.

[11] K. Chen, Z. Yang, Y. Feng, B. Zhu, J. Zhao, and T. Jiang, "Improving microwave antenna gain and bandwidth with phase compensation metasurface," AIP Advances, vol. 5, 2015.

[12] M. El Badawe, T. S. Almoneef, and O. M. Ramahi, "A true metasurface antenna," Scientific Reports, vol. 6, 2016.

[13] N. Rajak and N. Chattoraj, "Design and analysis of a bandwidth enhanced antenna based on metasurface for wireless applications," in Proceedings of the 2016 IEEE Uttar Pradesh Section International Conference on Electrical, Computer and 
Electronics Engineering (UPCON), pp. 367-371, Varanasi, India, December 2016.

[14] S. Zarbakhsh, M. Akbari, F. Samadi, and A. R. Sebak, "Broadband and high-gain circularly-polarized antenna with low RCS," IEEE Transactions on Antennas and Propagation, vol. 67, pp. 16-23, 2018.

[15] J. L. da Silva Paiva, J. P. da Silva, A. L. P. de Siqueira Campos, and H. D. de Andrade, "Using metasurface structures as signal polarisers in microstrip antennas," IET Microwaves, Antennas \& Propagation, vol. 13, pp. 23-27, 2018.

[16] H. L. Zhu, S. W. Cheung, K. L. Chung, and T. I. Yuk, "Linearto-circular polarization conversion using metasurface," IEEE Transactions on Antennas and Propagation, vol. 61, no. 9, pp. 4615-4623, 2013.

[17] W. Yang, Q. Meng, W. Che, L. Gu, and Q. Xue, "Low-profile wideband dual-circularly polarized metasurface antenna array with large beamwidth," IEEE Antennas and Wireless Propagation Letters, vol. 17, no. 9, pp. 1613-1616, 2018.

[18] H. Mosallaei and K. Sarabandi, "Design and modeling of patch antenna printed on magneto-dielectric embeddedcircuit metasubstrate," IEEE Transactions on Antennas and Propagation, vol. 55, no. 1, pp. 45-52, 2007.

[19] P. J. Ferrer González, Multifunctional Metamaterial Designs for Antenna Applications, Intechopen, London, UK, 2015.

[20] W. J. Krzysztofik and T. N. Cao, "Metamaterials in application to improve antenna parameters," Metamaterials and Metasurfaces, Intechopen, London, UK, 2018.

[21] I. Liberal, I. Ederra, J. Teniente, and R. Gonzalo, "Multifrequency radiator with spatial diversity based on metasurfaces," IEEE Antennas and Wireless Propagation Letters, vol. 11, pp. 519-522, 2012.

[22] J. Wang, H. Wong, Z. Ji, and Y. Wu, "Broadband CPW-fed aperture coupled metasurface antenna," IEEE Antennas and Wireless Propagation Letters, vol. 18, no. 3, pp. 517-520, 2019.

[23] Z. N. Chen, W. Liu, and X. Qing, "Low-profile broadband mushroom and metasurface antennas," in Proceedings of the 2017 International Workshop on Antenna Technology: Small Antennas, Innovative Structures, and Applications (iWAT), pp. 13-16, IEEE, Athens, Greece, March 2017.

[24] J. Hu, G. Q. Luo, and Z.-C. Hao, "A wideband quad-polarization reconfigurable metasurface antenna," IEEE Access, vol. 6, pp. 6130-6137, 2017.

[25] Z. Wu, L. Li, Y. Li, and X. Chen, "Metasurface superstrate antenna with wideband circular polarization for satellite communication application," IEEE Antennas and Wireless Propagation Letters, vol. 15, pp. 374-377, 2015.

[26] W. Liu, Z. N. Chen, and X. Qing, "60-GHz thin broadband high-gain LTCC metamaterial-mushroom antenna array," IEEE Transactions on Antennas and Propagation, vol. 62, no. 9, pp. 4592-4601, 2014.

[27] W. Yang, H. Wang, W. Che, and J. Wang, "A wideband and high-gain edge-fed patch antenna and array using artificial magnetic conductor structures," IEEE Antennas and Wireless Propagation Letters, vol. 12, pp. 769-772, 2013.

[28] K. Konstantinidis, A. P. Feresidis, and P. S. Hall, "Dual subwavelength fabry-perot cavities for broadband highly directive antennas," IEEE Antennas and Wireless Propagation Letters, vol. 13, pp. 1184-1186, 2014.

[29] K. Konstantinidis, A. P. Feresidis, and P. S. Hall, "Broadband sub-wavelength profile high-gain antennas based on multilayer metasurfaces," IEEE Transactions on Antennas and Propagation, vol. 63, pp. 423-427, 2014.

[30] K. Konstantinidis, P. S. Hall, and A. P. Feresidis, "Dual-slot feeding technique for broadband Fabry-Perot cavity antennas," IET Microwaves, Antennas \& Propagation, vol. 9, no. 9, pp. 861-866, 2015.

[31] S. X. Ta and I. Park, "Low-profile broadband circularly polarized patch antenna using metasurface," IEEE Transactions on Antennas and Propagation, vol. 63, no. 12, pp. 5929-5934, 2015.

[32] M. Li, Y. Zhang, and M.-C. Tang, "Design of a compact, wideband, bidirectional antenna using index-gradient patches," IEEE Antennas and Wireless Propagation Letters, vol. 17, no. 7, pp. 1218-1222, 2018.

[33] B. Majumder, J. Mukherjee, K. P. Ray, and K. Kandasamy, "Wideband compact directive metasurface enabled pair of slot antennas," Electronics Letters, vol. 51, no. 17, pp. 1310-1312, 2015.

[34] F. H. Lin and Z. N. Chen, "Truncated impedance sheet model for low-profile broadband nonresonant-cell metasurface antennas using characteristic mode analysis," IEEE Transactions on Antennas and Propagation, vol. 66, pp. 5043-5051, 2018. 